\title{
Low Cost Community Health Interventions to Address the Mental Health Crisis Arising From Greece's Financial Austerity Measures
}

\author{
Eleni Styliani Ramphos, $\mathrm{BHSc}^{1}$, Raywat Deonandan, $\mathrm{PhD}^{2}$
}

1 Global Health Sciences, University of California

2 Interdisciplinary School of Health Sciences, University of Ottawa

A B STRACT

In response to the European financial crisis of 2008-2009, Greece reduced funding for social spending as part of its austerity program, which may have reversed past progress in Greece's mental health system. Significant increases in depression and suicide rates coincided with the start of the crisis. A slower economic recovery may result from the combination of a less productive work force and out-migration of mental health professionals. In order to alleviate the detrimental effects of this crisis, mental health crisis training, as well as low cost community-based programs should be prioritized in Greece.

\section{RÉSUM É}

Dans le cadre du programme d'austérité qu'elle a mis sur pied en réaction à la crise économique européenne de 2008-2009, la Grèce a réduit ses dépenses dans les programmes sociaux. Or, ce geste peut avoir renversé les progrès qui avaient été réalisés dans le passé dans le système de santé mentale du pays. Une reprise économique plus lente pourrait découler de la combinaison d'une main d'œuvre moins productive et de l'exode des professionnels de la santé mentale. Afin d'alléger les effets nuisibles de la crise, la formation en gestion des crises de santé mentale, de même que l'offre de programmes communautaires peu coûteux devraient être priorisées en Grèce.

\section{INTRODUCTION}

At the epicenter of Europe's financial crisis, Greece has been greatly affected by austerity measures. Although designed to assuage financial distress, there is unsurprising evidence that these measures are negatively affecting several aspects of Greek society, which are dependent upon high levels of sustained public financing. Greece's social spending has declined dramatically since the crisis began in 2008, from almost $20 \%$ of GDP in 2007 to about $10 \%$ in 2012 , the largest decrease among OECD countries documented [1].

The country's mental health system is one of the sectors affected by the decline in spending, reflected in declines in funding of both direct psychiatric care and general sectoral support. This is particularly disappointing, as the system was working efficiently under Greece's so-called Psychiatric Reform, prior to the austerity measures [2]. Indeed, the new austerity measures are likely reversing many of the positive advancements made in Greece's mental health care in the past few decades. Since the start of the financial crisis, there have been significant increases in both depression and suicide rates, which is troubling for a society that is trying to recover economically.

This paper outlines a strategy to help assuage a slow decline in Greece's mental health structure, while remaining faithful to the ideals of the previously successful Greek Psychiatric

Keywords: Greece, financial crisis, mental health, psychiatric reform, suicide
Reform. These recommendations include: (1) enhancing mental illness prevention programs at the personal, familial, and social level; (2) investing in workplace engagement to improve diagnosis and rapid response; and (3) leveraging advances in telecommunication technologies to lower health delivery costs and expand access to services.

\section{THE PSYCHIATRIC REFORM IN THE MID-1980s}

In the 1980s, Greece implemented Psychiatric Reform to de-institutionalize psychiatric care from asylum-like institutions, establish numerous community services, create psychiatric departments in general hospitals, increase rural psychiatric care, and to ensure sufficient funding and access to care. The Psychiatric Reform was established to make care more efficient, and to reach populations outside of Greece's main urban areas through sectorization. Mental health services were carried out by Greece's public and private sectors, and non-profit units, and were supported with assistance from the European Union. The Reform had successful effects; however, full sectorization was not achieved, as a decided retreat from the progressive policies of the Reform had arisen due to Austerity [2, 3].

\section{THE EFFECTS OF AUSTERITY MEASURES ON MENTAL} HEALTH

In the current Austerity era, psychiatrists represent only 
$3.8 \%$ of all specialties in Greece, with less care offered in rural settings. The island of Samos, for example, has only 2 psychiatrists to service its population of 35,000 inhabitants [4]. Clearly, the dearth of relevant psychiatric professionals is a primary indicator of the system's vulnerability.

Data on the direct effects of Austerity on Greece's mental health profile is sparse. However, one recent study found that the prevalence of major depressive disorder (MDD) has increased by over $50 \%$ in one year [2]. In addition, official surveillance suggests that there was an increase in the overall suicide rate of $26.5 \%$ between 2010 and 2011, and a $43 \%$ increase compared to 2007, which was when the first signs of the economic downturn began [5]. In 2011, the Greek Health Minister, Andreas Loverdos, admitted that most studies were showing an increase in suicides of approximately $40 \%$ [6]. Two Greek nationwide telephone surveys conducted by Madianos et al., in samples of 2,197 and 2,192 respectively, found a 36\% increase in suicide attempts from 2009 to 2011 [7]. Point estimates of Greece's suicide and depression rates may be comparable to the EU norm, but the rapid acceleration of these rates since the financial crisis distinguishes Greece's situation [8].

The situation in Greece is troubling for several reasons: the upward trajectory of its rates of mental health morbidity, the temporal connection of this increase with the specific experience of Austerity, the loss of measurable progress achieved through the Psychiatric Reform, and the possibility that this trend may in fact undermine the very purpose for Austerity itself. The latter point is perhaps the most noteworthy. While no data yet exist to substantiate this suggestion, there remains the risk that underfunding a vital social pillar will reap several unintended negative consequences, including the out-migration of medical professionals, and a less productive workforce.

\section{LOW COST SUPPORTS FOR GREECE'S MENTAL HEALTH SYSTEM}

In countries where the treatment gap between mental health burden and care is growing, such as India (9), and increasingly in Canada (10), the World Health Organization recommends integrating mental health into primary care, presumably offering an affordable solution to an increasing need [11]. In concert with the shift of responsibility to primary care, several additional steps may be taken, as we describe below, addressing concerns in prevention, response, and sustainability.

\section{Addressing Prevention Needs - Awareness Meetings, Family Education \& Public Engagement}

Community Mental Health Programs can offer many services, including outpatient psychiatric care, community preparation workshops, health promotion, rehabilitation, and other similar resources. A successful example is Paripurnata, a Non-Governmental Organization located in Habra, West Bengal, India, which primarily provides outpatient psychiatric care, but also anti-stigma workshops and informational sessions, preventing mental health crises leading to a hospital admission or sui- cide. A recent evaluation of these programs found increased awareness, increased care to patients, and a decrease in negative viewpoints, and concluded that the program should be sustained. Similar programs would be worthwhile, so long as the community is willing and stakeholders are available [12].

It can be argued that the most important level for prevention of suicide and mental health crises is at the familial level. It has been shown that family psycho-education has many positive effects, including: reduction of relapse, reduction of readmissions to hospital, improvement of family involvement, and patient adherence to treatment. In terms of the caregivers, there was more knowledge of mental health problems, more empowerment, and reduced stress and worry in regards to their affected loved one. A successful example is the Support and Family Education (SAFE) Program: Mental Health Facts for Families, which provides a 90-minute workshop once a month, to be attended at the convenience of the families, which covers signs and symptoms, educates on available services, teaches about prevention, and offers families opportunities to ask questions. In addition, the workshop covers caregiver support to prevent caregivers from developing their own mental health conditions in response to their caregiver-related stress [13]. These programs increase knowledge and awareness, preventing individuals from seeking emergency care in crisis.

\section{Addressing Response Needs - Public \& Workplace Engagement}

Mental Health Care training can be offered in the workplace setting to general public servants, as well as emergency and primary care physicians. Mental Health First Aid (MHFA), originally developed in Australia, is well known and an accepted standard for mental health crisis vocational training. In a recent trial, individuals having taken the course experienced the following in comparison to the control groups: more confidence in assisting mental health patients, more likely to assist individuals in seeking professional help, reducing stigma, and more concordance with health professionals and treatments. It was also found to have improved the mental health of the individuals taking the courses [14].

Morawska et al. examined the effectiveness of this program design in multicultural communities. At its core, MHFA should educate the public to support those in immediate, lifethreatening crisis, and should offer instruction in symptoms, causes, treatments for depression, anxiety, psychosis, substance abuse, and crisis training including suicidal ideations, panic attacks, and drug overdose. In an examination of a successful, culturally sensitive program, there was an increase in recognizing mental health disorders, concordance between professionals on treatment, confidence in giving first aid treatment, decreased stigma, as well as continued competency following a 6-month post-test [15].

Most importantly, non-psychiatry medical workers should be trained in this intervention, as well. A successful 2-hour program was designed for medical residents based on 
MHFA, and was evaluated. Physicians showed improved confidence and attitudes, abilities to assess risk, listen to patients nonjudgmentally, give reassurance, and encourage further professional help, and self-help strategies [16]. A similar program was also conducted for general practitioners in the Gotland Study; however, it should be noted that in the case of general practitioners, not all programs have been successful [17]. Each program should be designed to fit each individual culture [18].

\section{Addressing Sustainability Needs - Technology-based Therapies}

Many nations are finding cost-saving solutions by relying increasingly on technological medical solutions, in particular capitalizing on recent advances in broadband telecommunication, thus reducing reliance on in-person care-giving.

E-Mental Health, in the scope of this article, refers to communication for the purposes of medical care, delivered via the Internet. It has been recommended by the Canadian Mental Health Commission as one of their top upcoming priorities and can be relatively low-cost, as it is often provided by those who are not psychiatrists; however, they are trained nonetheless to offer tele-therapies, internet-based interventions, design mobile applications, and self-help programs online $[19,20]$.

A specific design that has been evaluated is the use of Cognitive-Behavioral Therapy or Problem-Solving Therapy via online video-conference, which has been shown to lower depressive symptoms, and increase feelings of control in patients, a skill necessary to those living in Austerity. Warmerdam et al. have shown that it is the professional-patient relationship, and not the type of therapy offered, that determines the success of the program [21].

Suicide hotlines are also a useful technology to decreasing suicide rates. A randomized control trial examining a waitlist control group, Solution Focused Brief Therapy (SFBT), and Common Factors Therapy (CFT) groups, has shown significant improvements in all examined populations treated therapeutically. The distinction in this program is that this particular hotline does not merely offer brief assistance via telephone to discourage suicide, but rather follows up with sessions after the episode with secondary mental health care workers, in a program sponsored by the agency [22]. A variety of hybrid options are available to beset population, with varying combinations of interaction.

Clearly, the major barrier to implementing such technological interventions is start-up cost. However, any budgetary planning exercise would be well advised to consider the long term cost savings potential of an expanded reliance on technological assistance.

\section{CONCLUSION}

While it is unlikely that we will see a sudden policy reversal concerning the funding of Greece's mental health sector, other steps can be taken to relieve the damage being done by the nation's extreme financial measures. Of course, any of these strategies would have to be implemented with sensitivity to prevailing Greek values, and within the narrow confines of that nation's constrained budget. Communal Greek values are often dictated by the Greek Orthodox Church, which condemns suicide and thus, generally refuses to bury victims of suicide. Those implementing these community health measures must be culturally sensitive and expect a certain level of stigma [23]. However, this should not deter intervention, as failure to take constructive, incremental action now may result in increased suffering, as measured in rising rates of depression, suicide, and other manifestations of mental ill health.

The aforementioned solutions are ideal as they are low cost. In absence of our reforms, there are two alternatives: increased expensive specialist care, or no available treatments, causing great financial strain to an already vulnerable society. Removing shortages in formal mental health workers would result in a substantial amount of cost for the affected country. Shifting the tasks to available complimentary health workers, in low cost, preventative, responsive, and sustainable program options, would be less expensive solutions [24]. These simple, yet effective interventions, present Greece with a chance for resilience in the long term.

\section{REFERENCES}

1. Organization for Economic Co-operation and Development (OECD). Social Spending During the Crisis - Social Expenditure (SOCX) Data Update 2012. [Internet]. Paris (FR): OECD; Year 2012 [cited 20138 Dec]. Available from: http://www.oecd.org/els/soc/OECD2012SocialSpendingDuringTheCrisis8pages.pdf.

2. Karastergiou, A, Mastrogianni, A, Georgiadou, E, Kotrotsio, S Mauratziotou, K. The Reform of the Greek Mental Health Services. Journal of Mental Health. 2005; 14(2): 197-203.

3. Christodoulou, GN, Ploumpidis, DN, Christodoulou, NG, Anagnostopoulos, DC. The State of Psychiatry in Greece. International Review of Psychiatry. 2012; 24(4): 301.

4. Hellenic Statistical Authority ELSTAT. Physicians by Specialty and Dentists, by Geographic Region. [Internet]. Athens (GR): ELSTAT; Year 2012 [cited 2013 Dec 12]. Available from: http:// www.statistics.gr/portal/page/portal/ESYE/PAGE-themes?p_ param $=A 2103 \& r$ param $=$ SHE09\&y_param $=2012 \_00 \&$ mytabs $=0$

5. Press TV. Economic Crisis in Greece Hits Mental Health: Study. [Internet]. Tehran (IR): Press TV; 2013 Oct 3 [cited 11 Dec 2013]. Available from: http://www.presstv.com/detail/2013/10/03/327435/ crisis-in-greece-hits-mental-health/

6. Ekathimerini. Sharp Rises in Suicide Amid Crisis [Internet]. Athens (GR): Ekathimerini News; 2011 June 30 [cited 2013 Dec 7] Available from: http://www.ekathimerini.com/4dcgi/_w_articles_ wsite1_1_30/06/2011_396649

7. Madianos, M, Economou, M, Alexiou, T, Stefanis, C. Depression and Economic Hardship Across Greece in 2008 and 2009: Two Cross-Sectional Surveys Nationwide. Social Psychiatry and Psychiatric Epidemiology. 2011; 46(10): 943-52.

8. European commission, Mental Health Indicators [Internet]. Athens (GR): European Core Health Indicators; [cited 2014 Mar 31]. Available from: http://ec.europa.eu/health/mental_health/indicators/ index_en.htm

9. Subbaraman, R et al. The psychological toll of slum living in Mumbai, India: A mixed methods study. Social Science \& Medicine. 2014; 119: 155-169.

10. Canadian Psychiatric Association. Child psychiatry in Canada: Physician Resources [Internet]. Ottawa (ON); 2014 [cited 2014 Sept 21]. Available from: https://ww1.cpa-apc.org/Publications/Position_Papers/child.asp

11. World Health Organization. Integrating Mental Health into Pri- 
mary Care: A Global Perspective [Internet]. Geneva (CH); 2008 [cited 2014 Aug 23]. Available from: http://www.who.int/mental_ health/resources/mentalhealth_PHC_2008.pdf

12. Sahu, KK. Impact Evaluation of the Community Mental Health Program at Habra. Indian J Psychiatry. 2014; 56(2): 143-9.

13. Sherman, MD. The Support and Family Education (SAFE) Program: Mental Health Facts for Families. Psychiatr Serv. 2003; 54(1): 35-7.

14. Kitchener, BA, Jorm, AF. Mental Health First Aid Training in a Workplace Setting: A Randomized Controlled Trial. BMC Psychiatry. 2004; 4: 23.

15. Morawska, A, Fletcher, R, Pope, S, Heathwood, E, Anderson, E, McAuliffe, C. Evaluation of Mental Health First Aid Training in a Diverse Community Setting. International Journal of Mental Health Nursing. 2013; 22: 85-92.

16. Kato, TA et al. Development of 2-hour Suicide Intervention Program Among Medical Residents: First Pilot Trial. Psychiatry and Clinical Neurosciences. 2010; 64: 531-540.

17. Rutz, W, von Knorring, L, Walinder, J. Long-term Effects of an Educational Program for General Practitioners Given by the Swedish Committee for the Prevention and Treatment of Depression. Acta Psychiatr Scand. 1992; 85(1): 83-8.

18. Thompson, $\mathrm{C}$ et al. Effects of a Clinical-Practice Guideline and Practice-Based Education on Detection and Outcome of Depression in Primary Care: Hampshire Depression Project Randomised Controlled Trial. Lancet. 2000; 355(9199): 185-91.

19. Mental Health Commission of Canada. Creating Change: Annual Report 2012-2013 [Internet]. Ottawa (ON). 2013 [cited 2014 Aug 23]. Available from: http://www.mentalhealthcommission.ca/English/annual-report-2012-2013

20. Cavanagh, K, Millings, A. (Inter)personal Computing: The Role of the Therapeutic Relationship in E-mental Health. J Contemp Psychother. 2013; 43: 197-206.

21. Warmerdam, L, van Straten, A, Jongsma, J, Twisk, J, Cuijpers, P. Online Cognitive Behavioral Therapy and Problem-Solving Therapy for Depressive Symptoms: Exploring Mechanisms of Change. Journal of Behavior Therapy and Experimental Psychiatry. 2010; 41: 64-70.

22. Rhee, W, Merbaum, M, Strube, M, Self, S. Efficacy of Brief Telephone Psychotherapy with Callers to a Suicide Hotline. Suicide and Life-Threatening Behavior. 2005; 35(3): 317-328.

23. The Economist. A Hard Subject for a Sermon [Internet]. 2013 [cited 2014 Sept 21]. Available from http://www.economist.com/blogs/ erasmus/2013/10/greece-and-suicide.

24. Kakuma, R. Human Resources for Mental Health Care: Current Situation and Strategies for Action. Lancet. 2011; 378(9803); 16541663. 